\title{
CONFIGURACIÓN Y FUTURO DE LA CONURBACIÓN DE ELDA-PETRER (ALICANTE)
}

\author{
Ernesto Cutillas Orgilés \\ Departamento de Geografía Humana \\ Universidad de Alicante
}

\section{RESUMEN}

La conurbación de Elda-Petrer surge como consecuencia del desarrollo de la industria y del urbanismo a partir de los años 70. Ambas ciudades han crecido por separado sin llevar a cabo ninguna política de planificación urbana conjunta, hasta que los núcleos se han fusionado. Las relaciones funcionales existentes entre los ciudadanos y la construcción de nuevas viviendas han supuesto una agilización de los procesos sociodemográficos, en especial los referentes al envejecimiento de la población, a la inmigración y a la pérdida de vitalidad de determinados barrios en beneficio de otros. Se hace necesario una coordinación más eficiente en materia de planificación urbana entre ambos municipios, y también a la hora de gestionar los recursos públicos.

Palabras clave: Elda-Petrer, conurbación, sociodemografía.

\section{ABSTRACT}

The Elda-Petrer conurbation emerged as a consequence of the development of industry and urbanism from the 1970s onwards. Both cities have grown separately with no joint urban planning policy, until eventually the two towns merged. The functional relationships between the citizens and the construction of new housing has brought about the improvement of sociodemographic processes, particularly in relation to the ageing population, immigration and the loss of vitality in certain areas to the benefit of others. It has become necessary to implement a more efficient coordination with regards urban planning between the two towns, and also in public resource management.

Key words: Elda-Petrer, conurbation, sociodemographic. 


\section{El espacio urbano de Elda-Petrer}

La evolución de los espacios y de las sociedades es una constante en el tiempo. Cada generación aporta un grado de transformación al territorio que va dejando huellas reconocibles y yuxtapuestas a las anteriores. El resultado de este proceso es la identificación de una serie de áreas que, a distinta escala (desde la supranacional hasta la intraurbana), presentan heterogeneidad en cuanto a los agentes que participan de dichas transformaciones.

La privilegiada localización de Elda-Petrer en el denominado «Arco Mediterráneo» le confiere una ventajosa posición de cara a la presencia que puedan tener los flujos de capitales y de habitantes de esta Euroregión. Esta influencia se traduce en términos de competitividad, ya que nos encontramos ante unas ciudades cuya tradición empresarial tiene una clara vocación exportadora, además de una larga experiencia en la promoción de sus empresas. En los últimos años ha habido aportaciones tanto públicas como privadas orientadas a la construcción de nuevas infraestructuras, equipamientos y hacia la diversificación industrial. La finalidad de estas acciones es poner las bases para un territorio más accesible y vertebrado, de modo que se atraigan inversiones, se equilibre la estructura demográfica y se consoliden los mercados exteriores.

\subsection{Crecimiento urbano. El origen del actual urbanismo}

El urbanismo actual de Elda-Petrer responde esencialmente a las necesidades que durante la segunda mitad del siglo XX, tuvo la industria para hacer frente a la necesidad de viviendas para una población inmigrante que acudía desde otras partes de España como mano de obra. La aparición de cooperativas de viviendas y construcción de polígonos de viviendas fue dejando paso, con la llegada de la democracia, a una nueva concepción del urbanismo en la que valores como el patrimonio histórico y la sostenibilidad ambiental fueron calando en la sociedad y a su vez cohabitando con políticas urbanas contradictorias.

Es evidente que siempre que se ha estudiado el despegue urbano de Elda-Petrer, se ha tomado en cuenta una serie de factores que hacen referencia a los procesos de industrialización. Así, nos encontramos ante un territorio que desde finales del siglo XIX experimentó un progresivo proceso de transformación de su economía agraria por otra eminentemente industrial, y que tuvo su reflejo en el tejido urbano.

Cuadro 1

FACTORES QUE INCIDEN EN LA TRANSFORMACIÓN URBANA

\begin{tabular}{|c|c|c|c|}
\hline Factores demográficos & Factores económicos & Factores Tecnológicos & Cambios en la sociedad \\
\hline $\begin{array}{l}\text { - Crecimiento de la po- } \\
\text { blación por caída de la } \\
\text { mortalidad. } \\
\text { - No obstante se man- } \\
\text { tiene la natalidad con } \\
\text { un ligero descenso } \\
\text { - Abandono del pobla- } \\
\text { miento rural. } \\
\text { - Llegada de inmigran- } \\
\text { tes de localidades } \\
\text { próximas }\end{array}$ & $\begin{array}{l}\text { - Escasa rentabilidad } \\
\text { de la agricultura. } \\
\text { - Tradición en la fabri- } \\
\text { cación y comerciali- } \\
\text { zación del calzado. } \\
\text { - Aparición de las pri- } \\
\text { meras fábricas e in- } \\
\text { dustrias auxiliares. }\end{array}$ & $\begin{aligned} \text { - Tecnificación del pro- } \\
\text { ceso de producción } \\
\text { (nuevas materia pri- } \\
\text { mas y maquinaría). } \\
\text { — Especialización en el } \\
\text { trabajo. } \\
\text { — Llegada de maestros } \\
\text { zapateros (Baleares) } \\
\text { - Aparición de ferroca- } \\
\text { rril. } \\
\text { - Energía eléctrica }\end{aligned}$ & $\begin{array}{l}\text { - Aparición de la bur- } \\
\text { guesía. } \\
\text { - Construcción de } \\
\text { nuevas viviendas. } \\
\text { - Tímido proceso de } \\
\text { escolarización. } \\
\text { - La presencia de la } \\
\text { iglesia no es tan po- } \\
\text { tente como en otras } \\
\text { ciudades próximas } \\
\text { - Existencia de teatro } \\
\text { y cines }\end{array}$ \\
\hline
\end{tabular}

Elaboración propia. 
Un proceso clave durante este período es la intensificación de una serie de procesos: por un lado el estancamiento de la agricultura y por otro el progresivo despegue de la protoindustria del calzado basada en el esparto. Esta sustitución de la agricultura por la industria perdura hasta que a mitad del siglo XIX se consolida la industria zapatera como la primera actividad económica de la ciudad (VALERO ESCANDEL, J.R., 1991), y así va a seguir hasta nuestros días, siendo el motor económico de Elda-Petrer. Así pues, el crecimiento urbano de Elda y de Petrer a lo largo de estos años se va a apoyar en dos aspectos decisivos: un enorme desarrollo de la actividad zapatera y la llegada de inmigrantes que acuden en busca de trabajo.

Una de las primeras respuestas que había que dar ante la llegada de personas procedentes de distintas áreas rurales de España era la de proporcionarles vivienda, cuya construcción en buena parte fue realizada por los empresarios. La urgencia y celeritud con la que se diseñaron estas viviendas dieron, con el paso de los años, un aspecto de inconexión en la trama urbana, y como resultado, irregularidades morfológicas en el tejido urbano por ausencia de planificación.

Pero no sólo los empresarios fueron los responsables de la construcción de nuevas viviendas, ya que en un clima general de reformas interiores empiezan a surgir a principios del siglo XX los polígonos de viviendas promovidos por las cooperativas obreras. Uno de los principales rasgos de estas actuaciones es que van a aportar un trazado regular y rectilíneo. No obstante tampoco respondían a una adecuada planificación, y por lo tanto se comunicaban con el resto de la ciudad por calles y otros elementos consolidados ya existentes. Puede decirse que lo nиеvo y lo viejo en cierta medida presentaban cierta desconexión entre sí. No obstante estas actuaciones suponen en gran medida la modernización de la ciudad.

Así entre 1899 y 1917 la cooperativa La Prosperidad edificó 112 viviendas que se sitúan en la Calle Pedrito Rico, en dirección al cementerio viejo. La siguiente sociedad en construir nuevas viviendas fue El Progreso, que en 1916 levantó 550 edificaciones entre la Plaza Sagasta y el límite con el municipio de Petrer. Por último, en 1922 la cooperativa La Fraternidad se encargó de construir cerca de 1.000 viviendas entre las de El Progreso y el límite con Petrer. La Guerra Civil no trajo cambios significativos en la trama urbana, salvo la destrucción de la Iglesia de Santa Ana; lo verdaderamente significativo fue la adaptación de la industria zapatera a una industria de guerra. Además, en esta época los sindicatos y movimientos obreros cobran enorme importancia respecto a la política local.

Llegados a la mitad del siglo XX y con la Ley del suelo de 1956 vigente, la ciudad de Elda ha crecido bastante en la horizontal así como en su densidad. De hecho, según el Nomenclátor de 1960, el número de viviendas localizadas en la ciudad era 6.252, mientras que las diseminadas en el municipio sólo 772, mientras que para Petrer las viviendas existentes en la ciudad para esas fechas eran 2.559 y en el resto del municipio 252 . La morfología de las casas responde a una estructura de planta baja y por tanto de baja densidad. Pero por estas fechas, década de los años sesenta, el urbanismo adquirió otro cariz, ya que además del citado crecimiento en horizontal, también se inicia la edificación vertical; es la época de la construcción de enormes edificios que romperán con el sky line de la ciudad. Las inconexiones e irregularidades en la trama urbana, implantadas en el primer tercio del siglo $\mathrm{XX}$, van a chocar de lleno con el modelo urbanístico propio del desarrollismo. Ejemplo de ello es el barrio de Las Trescientas, que por entonces estaba alejado del núcleo urbano, y la Cooperativa de San Francisco de Sales que levantó siete bloques de viviendas en la salida de la ciudad hacia la carretera N-332 (dirección sur). Por otro lado se continuó con la construcción y/o adecuación de nuevos espacios con la finalidad de hacer accesibles los distintos barrios a un creciente número de ciudadanos que, desde regiones desfavorecidas de España, acudían a ambas ciudades como mano de obra para la industria. 
A partir de la década de los setenta, se deberá reflexionar sobre la accesibilidad, porque es cuando empieza a cobrar relevancia el tráfico rodado, más aún cuando desde el punto de vista urbanístico la ciudad no estaba preparada para absorber el incipiente volumen de circulación por dos motivos: a) la inexistencia de planificación durante los años anteriores, cuando primero se construía y más tarde se dotaba a esos espacios de las infraestructuras, equipamientos y servicios necesarios; b) la desconexión que presentaban entre sí los distintos barrios de la ciudad. Por este motivo, y también para «rellenar» los vacíos e irregularidades urbanas, se elaboró un Plan General de Alineaciones a inicios de la década de los sesenta, vigente hasta bien entrados los años setenta. Es durante estos años cuando una serie de crisis internacionales afectan a la producción de zapatos de Elda-Petrer y por tanto a la exportación, apreciándose que los procesos urbano-industriales comienzan a ralentizarse. El contexto político se situaba en las postrimerías de la dictadura y el movimiento sindical y obrero tenían enorme influencia en la población. Por estos años la ciudad de Elda está ya casi delimitada, a falta del Barrio del Polígono Almafrá que comienza a construirse en 1977.

GráfICo 1. Evolución de la población de hecho de Elda y Petrer durante el siglo XX

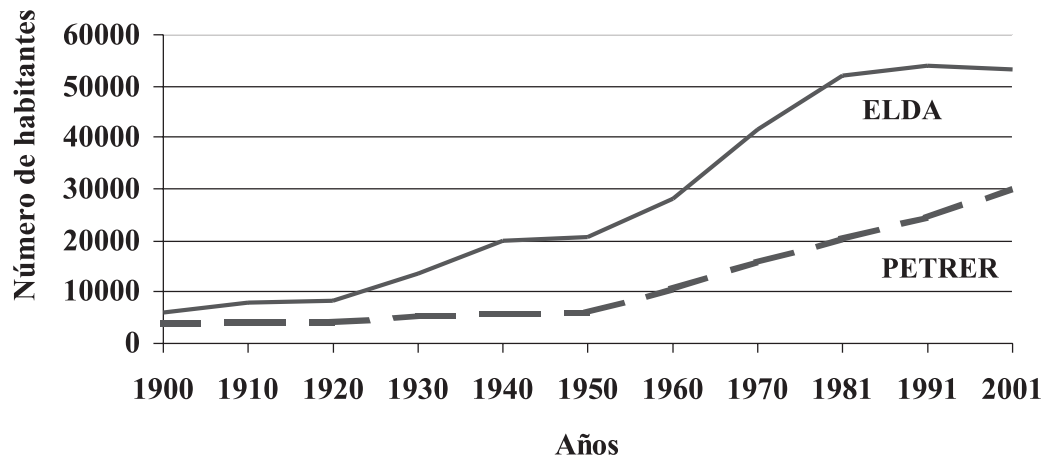

Fuente: INE, Censos de población de España. Debido a la nueva legislación, en 2001 sólo se censa población de derecho.

\begin{tabular}{|c|c|c|c|c|c|c|}
\hline Años & \multicolumn{3}{|c|}{ ELDA } & \multicolumn{3}{|c|}{ PETRER } \\
\hline & $\begin{array}{c}\text { Población } \\
\text { absoluta }\end{array}$ & $\begin{array}{c}\text { \% incremento medio } \\
\text { intercensal }\end{array}$ & $\begin{array}{c}\text { \% incremento } \\
\text { anual }\end{array}$ & $\begin{array}{c}\text { Población } \\
\text { absoluta }\end{array}$ & $\begin{array}{c}\text { \% incremento medio } \\
\text { intercensal }\end{array}$ & $\begin{array}{c}\text { \% incremento } \\
\text { anual }\end{array}$ \\
\hline 1900 & 6.131 & & & 3.928 & & \\
\hline 1910 & 8.028 & 30,9 & 2,73 & 3.992 & 1,6 & 0,16 \\
\hline 1920 & 8.078 & 0,6 & 0,06 & 4.120 & 3,2 & 0,32 \\
\hline 1930 & 13.445 & 66,4 & 5,23 & 5.290 & 28,4 & 2,53 \\
\hline 1940 & 20.050 & 49,1 & 4,08 & 5.506 & 4,1 & 0,40 \\
\hline 1950 & 20.699 & 3,2 & 0,32 & 6.145 & 11,6 & 1,10 \\
\hline 1960 & 28.151 & 36,0 & 3,12 & 10.615 & 72,7 & 5,62 \\
\hline 1970 & 41.511 & 47,4 & 3,96 & 15.804 & 48,9 & 4,06 \\
\hline 1981 & 52.185 & 25,7 & 2,31 & 20.361 & 28,8 & 2,57 \\
\hline 1991 & 54.010 & 3,5 & 0,34 & 24.383 & 19,7 & 1,82 \\
\hline 2001 & 53.103 & $-1,7$ & $-0,17$ & 30.556 & 25,3 & 2,28 \\
\hline
\end{tabular}


El crecimiento urbano de la ciudad durante estos períodos ha ido también ligado a una evolución demográfica muy similar a las sociedades industriales de gran parte de las ciudades españolas. Así se distinguen fases de crecimiento, coincidiendo con el auge del desarrollismo y la inmigración procedente de regiones agrícolas deprimidas de España, atraída por la posibilidad de trabajo. Fases de estancamiento, en relación con períodos de crisis y reestructuraciones internacionales de mercados. Y fases de recesión, propias de espacios postindustriales, que aprovechando nuevos espacios periurbanos con mejores condiciones y muy bien conectados con la ciudad, centros de trabajo y lugares de servicios, suponen una «válvula de salida» para las ciudades congestionadas y con problemas de falta de espacio y de movilidad, sin olvidar el precio del suelo y las incomodidades que presenta la ciudad de Elda, cuyo antiguo planeamiento urbano repite irregularidades que empujan a los ciudadanos a la búsqueda de residencias en su periferia, en este caso hacia Petrer.

Las características indicadas van a incidir de manera muy directa en la evolución social de la población, lo que tendrá un notorio reflejo en la compartimentación social de la ciudad. Es decir, estos elementos serán determinantes a la hora de identificar áreas urbanas socialmente contrastadas y que, además, han experimentado a lo largo de estos años procesos de evolución social.

Esta tendencia se ve intensificada durante la etapa del desarrollismo, si bien estos años suponen un crecimiento de la ciudad, ya que por esta época en la periferia de las ciudades comienzan a levantarse bloques de viviendas destinadas también a esa población que abandona el medio rural para trasladar su residencia a las ciudades. De modo que a mediados de los años setenta hay una zonificación social de la ciudad en relación a las características socioeconómicas de los habitantes de los barrios; dichas características se irán haciendo más evidentes conforme los vecinos de estos barrios vayan envejeciendo. En este contexto entra en juego un factor determinante para el crecimiento urbano: se estanca el crecimiento demográfico, pues tanto la inmigración como la natalidad se reducen. La industria ha llegado a su techo y es el momento en que se desarrollan los servicios. Antes los niños suponían una ayuda a la economía familiar, en cambio, ahora son una carga en el sentido que sólo suponen gasto, y por tanto es preferible tener menos hijos, más aún en ciudades donde las mujeres, pese a ejercer una actividad laboral y los logros sociales obtenidos, también deben atender la casa y la familia.

En el terreno del crecimiento espacial de la ciudad, señalemos que, por un lado, los hijos de los antiguos inmigrantes buscarán su residencia fuera del barrio de sus padres, ya que éste, con frecuencia, no reúne condiciones necesarias (son barrios mal planificados, los edificios han envejecido con rapidez debido a su muy baja calidad, conviven los talleres con las viviendas, los equipamientos son insuficientes, la circulación rodada es incómoda, hay problemas de aparcamiento...). En principio resultará complicado encontrar una vivienda en el centro urbano debido al elevado coste del precio del suelo, y que ya de por sí estamos en un tejido urbano consolidado. El resultado es que de nuevo habrá procesos de construcción en la periferia ante la demanda de nuevas viviendas, si bien este crecimiento viene respaldado por un PGOU (Plan General de Ordenación Urbana) porque ésta es la época cuando empiezan a aprobarse y a aplicarse las medidas de planeamiento urbano.

Ocurre sin embargo un proceso inverso al inicial. Si antes primero crecía el número de habitantes y más tarde lo hacía la ciudad, ahora sucede al revés, la población se estabiliza pero la ciudad continúa creciendo. En un principio esta dinámica supone una mejora de la calidad de vida: no hay hacinamiento en las viviendas, aumenta el tamaño de las mismas, los espacios verdes cobran mayor importancia, se sacan las industrias y actividades molestas se trasladan al exterior de la ciudad, se construyen nuevas infraestructuras y equipamientos... 
A este proceso debemos añadir que la tendencia demográfica, desde hace unos años, es hacia un envejecimiento acelerado. Pese a los beneficios que en un principio pueda suponer el tener una residencia (bungalow) en la periferia urbana, con el tiempo puede devenir en incomodidad, porque el uso del automóvil se convierte en algo de primera necesidad, los niños se hacen mayores, las parejas envejecen, la sensación de aislamiento es mayor, y si a esto añadimos que en estos lugares no existe una oferta de servicios, comercios o dotaciones que cohesionen y articulen estos lugares, los inconvenientes se disparan. Pero no podemos olvidar la presencia del municipio de Petrer, que ha crecido de modo notable como resultado de la atracción que ejercía sobre los eldenses que no encontraban suelo residencial asequible en su municipio hasta que se pusieron en valor los terrenos de la avenida de Ronda, en el sur, debido al agotamiento del PGOU de Elda de 1985.

A modo de recapitulación y tratando de analizar el proceso de consolidación de la conurbación, puede apreciarse que en 1920 (mapa 1), los núcleos urbanos de Elda y Petrer aparecen separados, pero es a partir de un proceso de crecimiento urbano en las dos ciudades que llega hasta 1956, cuando de modo paulatino van aproximándose los núcleos urbanos a costa de ganar suelo obtenido de antiguos espacios agrarios que marcaban la frontera entre ambas ciudades (mapa 2). No obstante, y coincidiendo con el auge de la industria y llegada de inmigrantes procedentes de otras regiones españolas, empieza a consolidarse la conurbación (mapa 3), siendo a partir de 1976 cuando aparecen delimitados los principales ejes urbanos, que con la llegada de la democracia suponen la consolidación del tejido urbano existente en las dos ciudades. El resultado de todo ello es la aparición de un núcleo urbano, que, si bien posee dos administraciones municipales distintas, representa una misma unidad funcional con una gran intensidad en las relaciones entre los ciudadanos (mapa 4).

\section{Elda-Petrer 2003, caracterización sociodemográfica}

\subsection{Aspectos demográficos}

Para aproximarnos a la realidad sociodemográfica de Elda es necesario tener en cuenta ciertas características urbanas y demográficas de Petrer. Pese a la existencia de dos unidades administrativas, ambas ciudades mantienen unas relaciones tanto ciudadanas como funcionales sin las cuales no podría entenderse esta aglomeración mayor de 85.000 habitantes.

Cuadro 2.

SALDO NATURAL Y SALDO MIRATORIO DE ELDA Y PETRER

\begin{tabular}{|c|c|c|c|c|c|c|}
\hline & \multicolumn{3}{|c|}{ ELDA } & \multicolumn{3}{|c|}{ PETRER } \\
\hline & \multirow{2}{*}{$\begin{array}{c}\text { Saldo } \\
\text { Natural }\end{array}$} & \multicolumn{2}{|c|}{ Saldo migratorio respecto a: } & \multirow{2}{*}{$\begin{array}{c}\text { Saldo } \\
\text { Natural }\end{array}$} & \multicolumn{2}{|c|}{ Saldo migratorio respecto a: } \\
\hline & & $\begin{array}{c}\text { Comunidad } \\
\text { Valenciana }\end{array}$ & $\begin{array}{c}\text { Otras } \\
\text { Autonomías }\end{array}$ & & $\begin{array}{l}\text { Comunidad } \\
\text { Valenciana }\end{array}$ & $\begin{array}{c}\text { Otras } \\
\text { Autonomías }\end{array}$ \\
\hline 1995 & 106 & -392 & 127 & 115 & 334 & 24 \\
\hline 1996 & 111 & -285 & 20 & 153 & 294 & 26 \\
\hline 1997 & 61 & -288 & 35 & 172 & 242 & 32 \\
\hline 1998 & 69 & -310 & 63 & 131 & 324 & 51 \\
\hline 1999 & -16 & -342 & 81 & 139 & 260 & 35 \\
\hline 2000 & 103 & -589 & 88 & 195 & 486 & 23 \\
\hline
\end{tabular}

Fuente: Instituto Valenciano de Estadística. Página web del IVE. 
Mapa 1. Evolución urbana Elda-Petrer. Proceso de consolidación

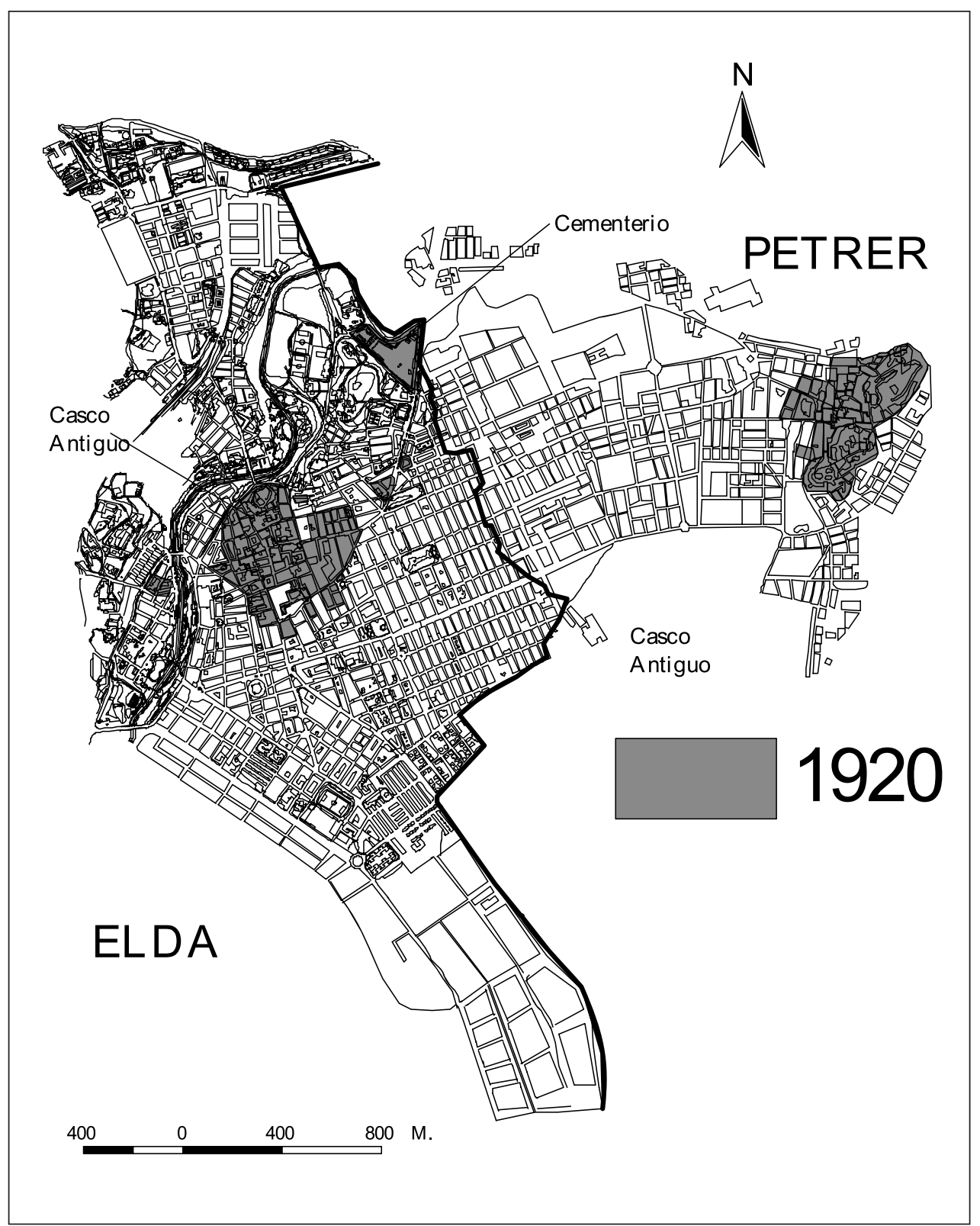

Fuentes: Instituto Cartográfico Valenciano. Diagnosis del Plan General de Ordenación Urbana de Elda. Trabajo de campo. Elaboración propia. 
MAPa 2. Evolución urbana Elda-Petrer. Proceso de consolidación

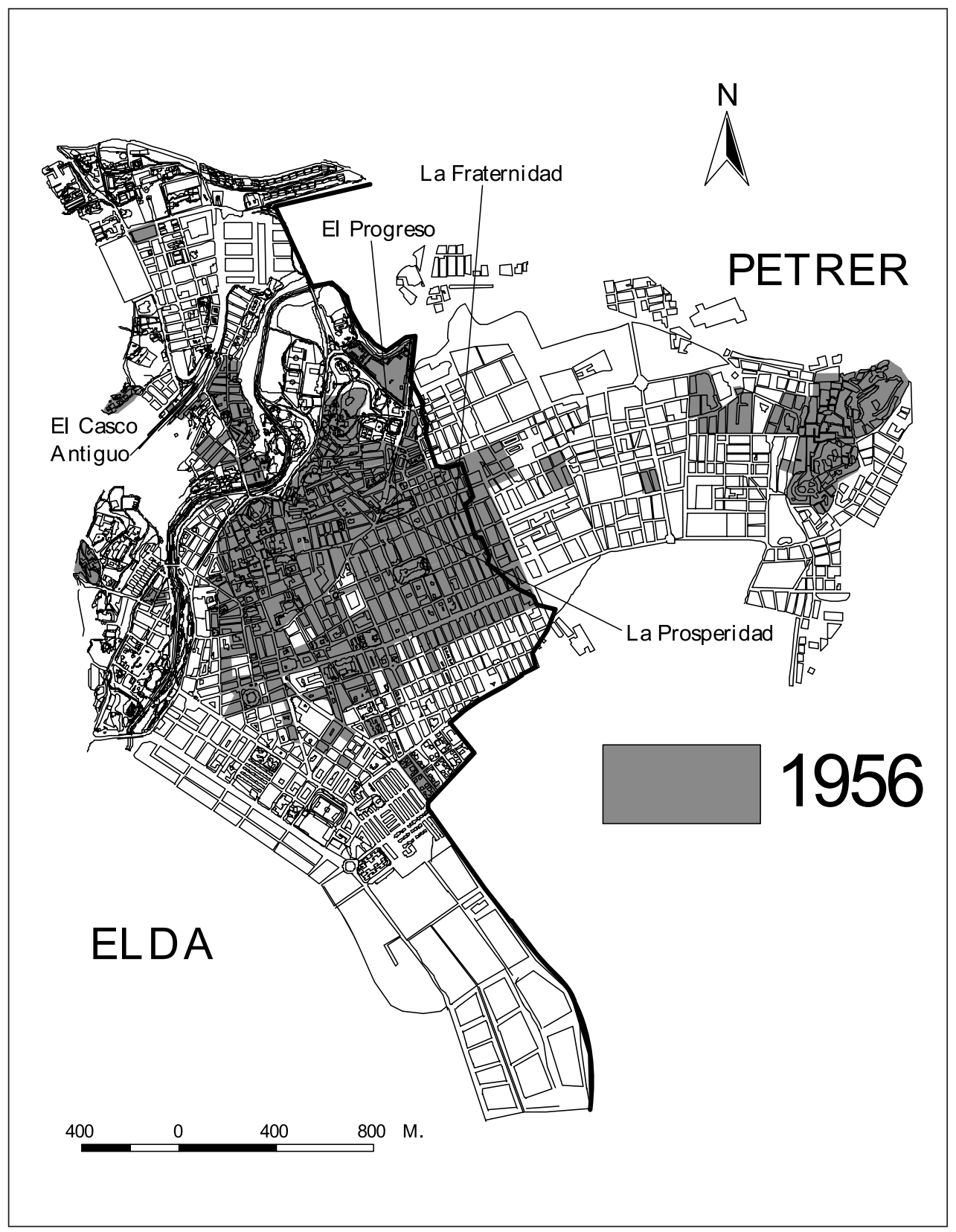

Fuentes: Instituto Cartográfico Valenciano. Diagnosis del Plan General de Ordenación Urbana de Elda. Trabajo de campo. Elaboración propia. 
MAPA 3. Evolución urbana Elda-Petrer. Proceso de consolidación

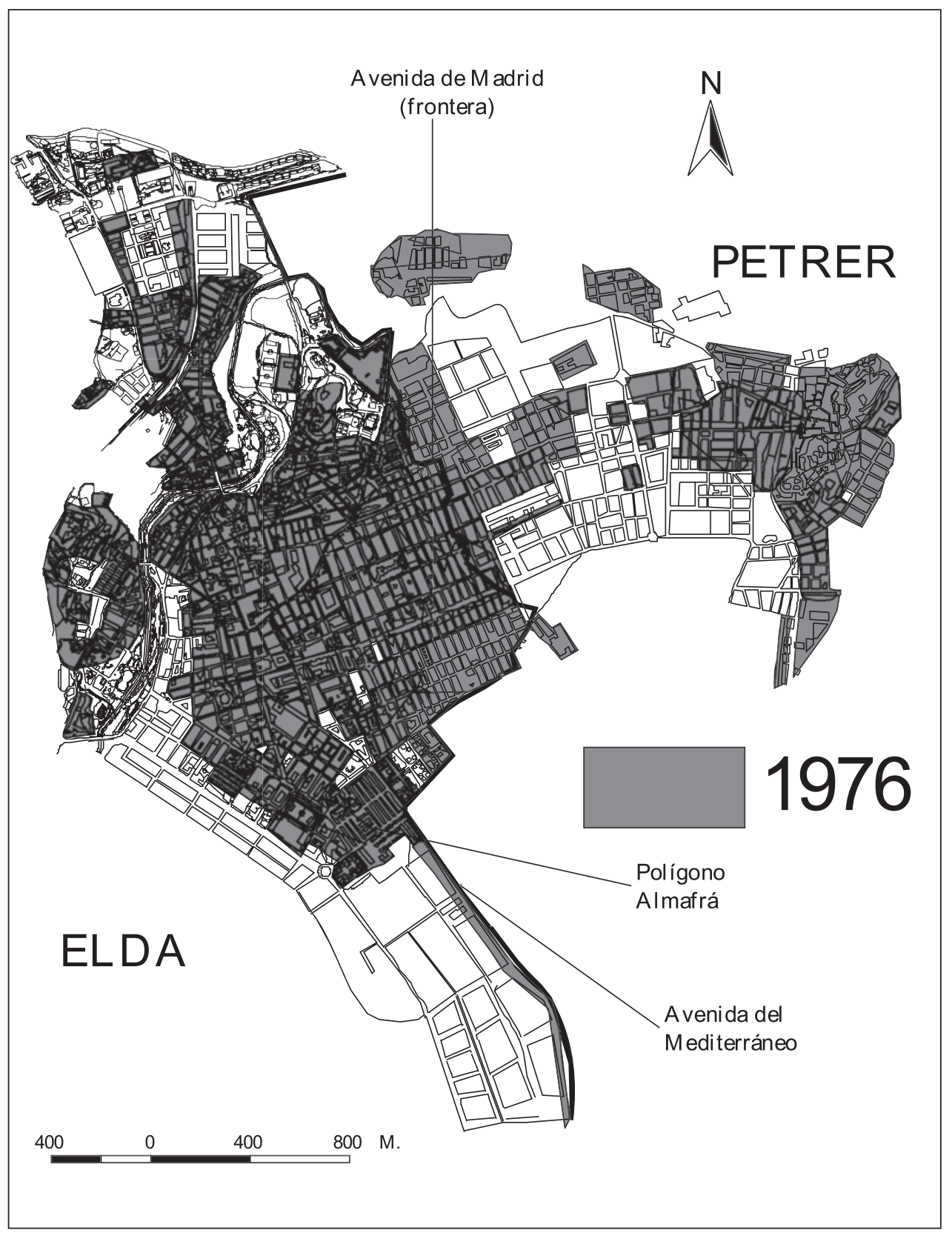

Fuentes: Instituto Cartográfico Valenciano. Diagnosis del Plan General de Ordenación Urbana de Elda. Trabajo de campo. Elaboración propia. 
MaPa 4. Evolución urbana Elda-Petrer. Proceso de consolidación

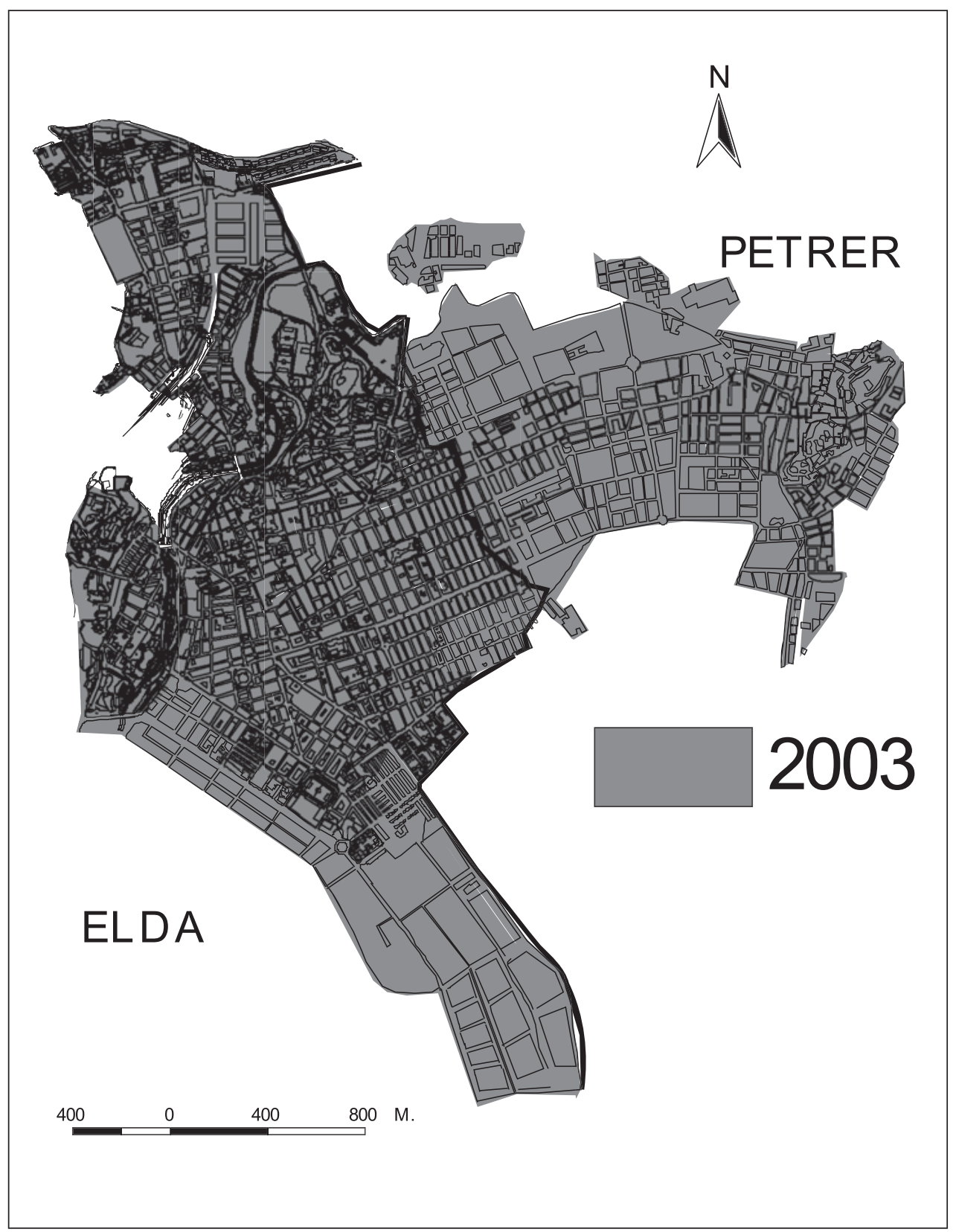

Fuentes: Instituto Cartográfico Valenciano. Diagnosis del Plan General de Ordenación Urbana de Elda. Trabajo de campo. Elaboración propia. 
Durante la mitad de la década de los años noventa del siglo XX, Elda experimentó un retroceso en su población entre cuyos motivos destaca la puesta en valor de nuevo suelo residencial en el municipio vecino, mientras que al mismo tiempo el PGOU de Elda de 1985 había quedado obsoleto y no respondía a las necesidades reales de su población. La consecuencia es que entre 1991 y 2001 la población de Petrer creció un 24,9\%, como resultado no sólo del movimiento natural, sino sobre todo por la llegada de nuevos habitantes procedentes de Elda, en su mayoría población joven, además de la población inmigrada. Sin embargo el intervalo de variación intercensal de Elda para ese mismo periodo era de $-1,7 \%$ (ver gráfico 1 ).

Aunque es evidente que ambas ciudades han crecido en su conjunto, se ha producido una redistribución de población entre ambos municipios. En este sentido el retroceso experimentado por Elda se ajusta en parte a los modelos de evolución urbana de las ciudades industriales medias españolas, en donde a un crecimiento vertiginoso a partir de la década de los sesenta, le sigue un progresivo estancamiento desde mitad de los años ochenta y hasta primeros de los noventa, sufriendo durante esta década una ligera pérdida de población a favor de las ciudades más pequeñas situadas en sus proximidades.

Elda creció mucho durante muy poco tiempo, y eso unido a la falta de adecuada planificación y de herramientas para una correcta ordenación del territorio, tiene como resultado la configuración de una ciudad que no será capaz de dar respuesta a las futuras necesidades de crecimiento, ni a las necesidades de regulación y reordenación de los espacios urbanos interiores consolidados. Del mismo modo, el PGOU de 1985, vigente en 2004, presenta algunas carencias al respecto, baste decir que para el año 2000 en sus proyecciones de población, preveía entre 70.000 y 100.000 habitantes. De modo que había que planificar con ese objetivo. No obstante señalemos que ni el crecimiento urbano ni el demográfico es siempre sinónimo de desarrollo. De este modo, para garantizar la calidad de vida urbana en el ámbito Elda-Petrer es necesario superar la escala local y pensar desde el punto de vista supramunicipal; de este modo se conseguiría una gestión más eficaz de los recursos, que incidiría en la mejora de la calidad de vida. Esto es así porque ambas ciudades están conurbadas y sus ciudadanos comparten los mismos espacios, conviene pues sumar y no restar.

\subsection{Los nuevos procesos constructivos}

Es evidente que en función de los saldos migratorios recientes, Petrer ha sido el foco receptor de población eldense que busca nuevas viviendas. Este hecho se materializa a la hora de comparar la evolución en la construcción de edificios de nueva planta en los últimos años del siglo XX.

Durante los últimos años, hay una relación directa entre variación de población y construcción de viviendas a favor de Petrer, es decir las diferencias, exceptuando la de 1995, benefician siempre a Petrer. Esta tendencia es necesaria tenerla en cuenta si se quiere entender la actual realidad sociodemográfica de Elda. No obstante, como ya hemos señalado con anterioridad, hay que asumir que en la práctica, pese a no existir una misma unidad administrativa, ambas ciudades tienen funciones complementarias y presentan ejemplos y evoluciones urbanísticas que responden a los modelos territoriales de las ciudades medias. Si bien encontramos unos tejidos urbanos consolidados, las nuevas formas de urbanismo guardan relación con modelos de ciudad abierta y de ciudad cerrada.

Una breve aproximación a la clasificación del suelo de ambos municipios en 1998, muestra cómo la anterior tendencia se cumple, ya que si bien Elda posee una mayor superficie de Suelo Urbano con 556,70 ha frente a las 313.24 ha de Petrer, éste presenta mayor 
Cuadro 3

EDIFICACIÓN DE NUEVA PLANTA

\begin{tabular}{|c|c|c|c|c|c|c|c|c|c|}
\hline AÑ & \multicolumn{2}{|c|}{$\begin{array}{c}\text { Total edificios a } \\
\text { construir }\end{array}$} & \multicolumn{2}{|c|}{$\begin{array}{c}\text { Edificios a construir } \\
\text { residenciales }\end{array}$} & $\begin{array}{c}\text { Edificios a construir } \\
\text { no residenciales }\end{array}$ & \multicolumn{4}{|c|}{ Total Viviendas } \\
\hline & ELDA & PETRER & ELDA & PETRER & ELDA & PETER & ELDA & PETRER & SALDO \\
\hline 1995 & 144 & 155 & 131 & 139 & 13 & 16 & 380 & 377 & +3 \\
\hline 1996 & 26 & 215 & 20 & 204 & 6 & 11 & 174 & 335 & -161 \\
\hline 1997 & 99 & 183 & 86 & 170 & 13 & 13 & 212 & 277 & -65 \\
\hline 1998 & 93 & 203 & 67 & 186 & 26 & 17 & 227 & 580 & -353 \\
\hline 1999 & 98 & 91 & 84 & 83 & 14 & 8 & 280 & 300 & -20 \\
\hline
\end{tabular}

Fuente: Ministerio de Fomento. Subsecretaria. D.G. de Programación Económica y Presupuestaria. Edificación y Vivienda.

Cuadro 4

ELDA-PÈTRER 1998. CLASIFICACIÓN Y CALIFICACIÓN DEL SUELO (EN HECTÁREAS)

\begin{tabular}{|c|c|c|c|c|c|c|c|}
\hline & & \multicolumn{3}{|c|}{ ELDA (Superficie 45,80 km²) $^{2}$ (4470ha) } & \multicolumn{3}{|c|}{ PETRER (Superficie 104,20 km²) $(10500,11 \mathrm{ha})$} \\
\hline \multirow{4}{*}{ 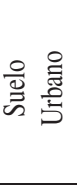 } & Residencial & 344,86 & \multirow{11}{*}{ 焉 } & \multirow{4}{*}{$\begin{array}{l}\stackrel{8}{\circ} \\
\frac{8}{n}\end{array}$} & 243,69 & \multirow{11}{*}{ 突 } & \multirow{4}{*}{ 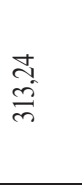 } \\
\hline & Industrial & 32,74 & & & 19,78 & & \\
\hline & Terciario & 0,00 & & & 9,14 & & \\
\hline & Dotacional & 179,10 & & & 40,63 & & \\
\hline \multirow{4}{*}{ 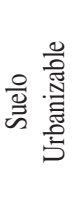 } & Residencial & 210,45 & & \multirow{4}{*}{$\begin{array}{l}20 \\
\stackrel{2}{0} \\
\approx\end{array}$} & 228,08 & & \multirow{4}{*}{$\begin{array}{l}\text { న̂ } \\
\text { के }\end{array}$} \\
\hline & Industrial & 17,2 & & & 101,18 & & \\
\hline & Terciario & 0,00 & & & 2,33 & & \\
\hline & Dotacional & $3,00^{1}$ & & & 45,34 & & \\
\hline \multirow{3}{*}{ 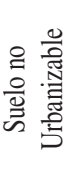 } & Dotacional & 36,75 & & \multirow{3}{*}{$\begin{array}{l}\text { J } \\
\text { i } \\
0 \\
0 \\
0\end{array}$} & 0,00 & & \multirow{3}{*}{$\begin{array}{l}\text { すे } \\
\text { ஓे }\end{array}$} \\
\hline & Protegido & 1959,48 & & & 8247,93 & & \\
\hline & No protegido & 1686,41 & & & 1562,01 & & \\
\hline
\end{tabular}

Fuente: Conselleria de obras públicas, transporte y urbanismo. Página web del IVE. Elaboración propia.

cantidad de Suelo Urbanizable: 376,93 ha por las 230,65 ha de Elda. Respecto al Suelo no Urbanizable, y atendiendo a las dimensiones de ambos términos municipales, señalemos que al ser mayor la extensión del término municipal de Petrer tiene más suelo clasificado como no urbanizable (cuadro 5).

Conviene hacer una referencia a la calificación del Suelo Urbanizable y Suelo No Urbanizable. Ambos municipios presentan diferencias en cuanto al reparto de superficie destinada a distintos usos. En general Petrer tiene en reserva mucho más suelo residencial,

\footnotetext{
$1 \quad$ Las dotaciones se encuentran en el suelo residencial.
} 
industrial, dotacional y terciario. Que se ejecute o no dependerá de la política urbanística municipal, si bien los augurios muestran que el crecimiento urbano de Petrer no tiene visos de detenerse, por lo menos a medio plazo. Cuestión muy a tener en cuenta respecto a la planificación de los equipamientos y dotaciones necesarias para satisfacer las necesidades de una población que va en aumento. Por otro lado, el caso de Elda es distinto, ya que si bien tiene unos límites de crecimiento urbano definidos, no lo es así el de la población, aunque ésta no parece que vaya a aumentar a corto plazo, salvo por la hipotética puesta en edificación de zonas declaradas Suelo no Urbanizable no Protegido.

En cualquiera de los casos, parece que va llegando el momento de ralentizar los crecimientos urbanos para dirigir los esfuerzos a consolidar lo existente. El territorio tiene unos límites y la sostenibilidad del mismo no puede ser mantenida por unas sociedades donde su modelo económico presenta muestras de desajustes estructurales.

La sostenibilidad de las nuevas ciudades debe hacerse por la consolidación y mejora de los espacios ya ocupados e intentado, entre todos los agentes políticos, económicos y sociales, compatibilizar los nuevos espacios construidos, con el fin de acercarlos a la ciudad y no que la ciudad se acerque a ellos. En ese sentido el reto para ambas ciudades consiste en corregir el crecimiento urbanístico «a saltos» y sin planificar (PONCE HERRERO, G., 2001). Hay que apostar por reinvertir en los espacios interiores de la conurbación, en donde el transcurrir de los años y la superposición de distintos usos del suelo, ha dado como resultado la existencia de incompatibilidades en un mismo espacio,

MAPA 5. Elda-Petrer 2003, localización de los barrios²

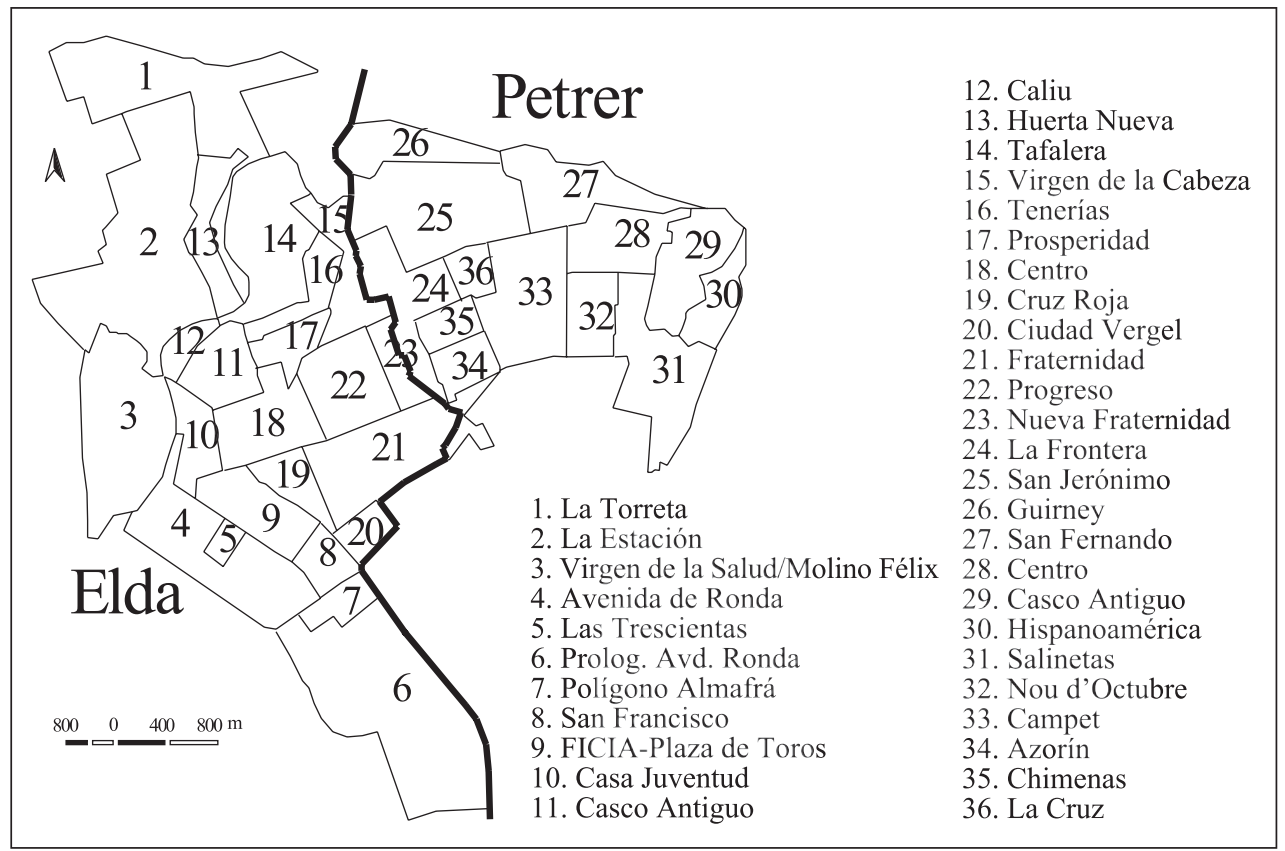

2 La división de los barrios se ha realizado sobre la delimitación de las secciones padronales existente en el PGOU de Elda y Petrer, además de criterios de reconocimiento de hitos y espacios claramente reconocibles y localizables por los ciudadanos de la conurbación. 
por ejemplo fábricas al lado de colegios o en zonas densamente pobladas. A ello añadamos que la red viaria no fue planificada correctamente, y que ésta actualmente no es capaz de absorber el creciente número de vehículos (en 2002 Elda tenía 30.694 vehículos de motor y Petrer 15.282).

\subsection{La estructura de la población por edad}

El hecho que caracteriza la aglomeración Elda-Petrer es la movilidad de ciudadanos entre ambos municipios. Las áreas que mayor dinamismo presentan están relacionadas con esta movilidad interurbana. Los mayores contingentes de población joven se hallan en los espacios periféricos de ambas ciudades, si bien en el caso de Petrer una parte de estos coinciden con la frontera urbana eldense, en donde aprovechando antiguas zonas de cultivo abandonas se promocionó la construcción de viviendas desde el Campet hasta la Avenida de Madrid en la frontera con Elda. En el año 2003 el 21,8\% de la población conjunta de ambos municipios tiene edades que comprenden hasta los de 19 años. Si separamos las ciudades, la tasa de este grupo de edades es superior en Petrer, con un $23,4 \%$, mientras que en Elda la cifra es del 21,1\%. Las mayores tasas de este grupo se encuentran en la zona de El Campet y las Chimeneas en Petrer y en Elda en el Molino de Félix, prolongación de la Avenida de Ronda en dirección Polideportivo y en la Tafalera. La presencia de población joven en los cuatro primeros barrios tiene como respuesta la existencia de viviendas de reciente construcción y de los hijos de las familias jóvenes que allí viven. Son las viviendas más recientes de la conurbación. Sin embargo conviene introducir algún matiz en la situación de la Tafalera, debido a la existencia de mucha población joven en un espacio degradado (mapa 6).

La situación anterior guarda gran paralelismo con la localización de la población mayor de 65 años. Para la conurbación, este grupo supone el 14,9\% del total, si bien en el caso de Petrer es del 13,1\% y en Elda el 15,8\%. No obstante encontramos una serie de espacios en ambos municipios donde la población está más envejecida. Para Petrer estos espacios coinciden con los barrios del centro, el Castillo y el Casco Viejo. En Elda son San Francisco, alrededores de la Plaza de Toros, el Progreso, Tenerías-Monte Calvario y partes de ambas Fraternidades. Son zonas que en el censo de 1991 ya presentaban la misma situación y que durante los últimos 12 años se ha agudizado. No obstante, otro sector urbano que en 1991 presentaba la misma situación era el barrio de las Trescientas, pero que transcurrido un tiempo se ha rejuvenecido, en especial por la puesta en valor de nuevas viviendas en sus proximidades como en la Avenida de Ronda y por la llegada de inmigrantes a esos espacios (mapa 7).

\section{4. Índices de dependencia y de maternidad}

Los índices de dependencia aplicados a la realidad demográfica de Elda-Petrer son significativos por cuanto nos muestran las actuales y futuras pautas de comportamiento de la dinámica poblacional de ambos municipios, entendidos como un gran conjunto. Si bien puede apreciarse un aumento reciente de la edad de la población, existen rasgos relacionados con el crecimiento urbano que determinan la configuración de espacios donde la dependencia es más alta. El índice de dependencia para ambos municipios es de 53,1\%, es decir por cada 100 habitantes en edad de trabajar, hay 53 personas entre 0-19 años y con 65 y más años. La cifra anterior se desglosa para los jóvenes en 31,8\% y en los viejos $21,3 \%$. Pero para cada municipio estas cifras muestran las diferencias producidas por la dinámica de la población que experimenta cada uno de ellos. De este modo Petrer tiene 
MaPa 6. Elda-Petrer 2003. Proporción de población entre 0 y 19 años

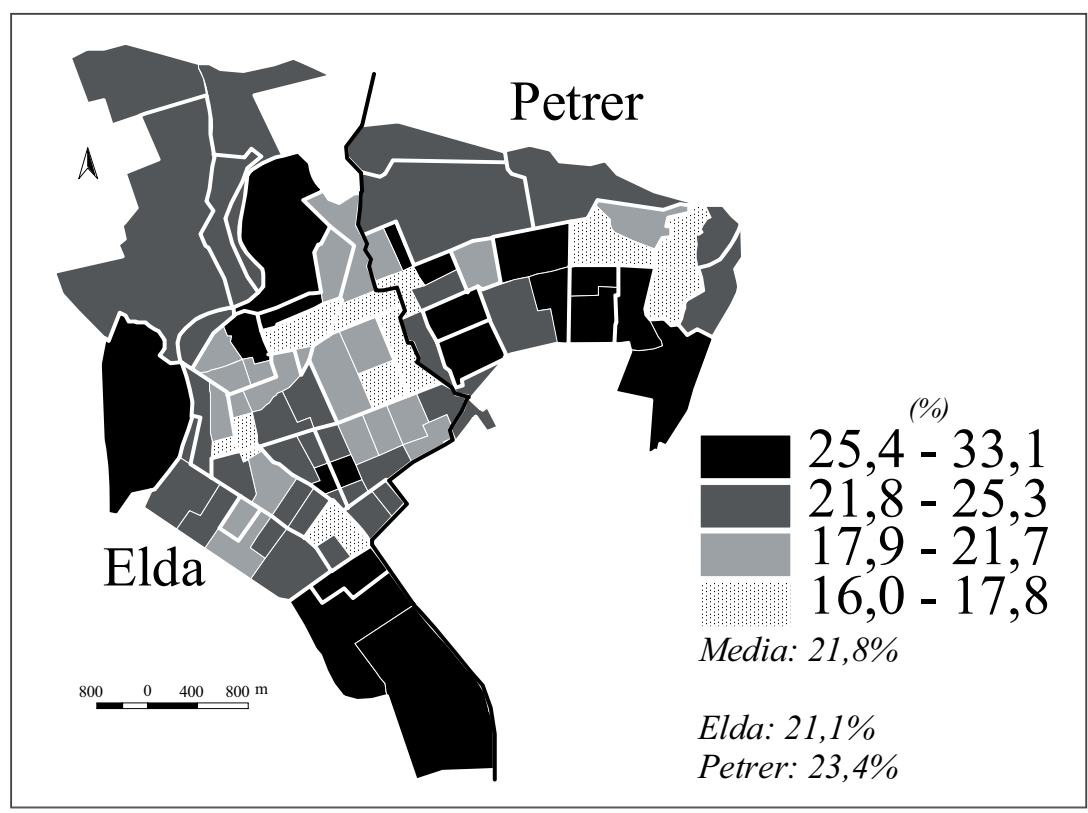

Fuente: Padrón municipal de habitantes 2003. Elaboración propia.

MAPA 7. Elda-Petrer 2003. Proporción de población a partir de 65 años

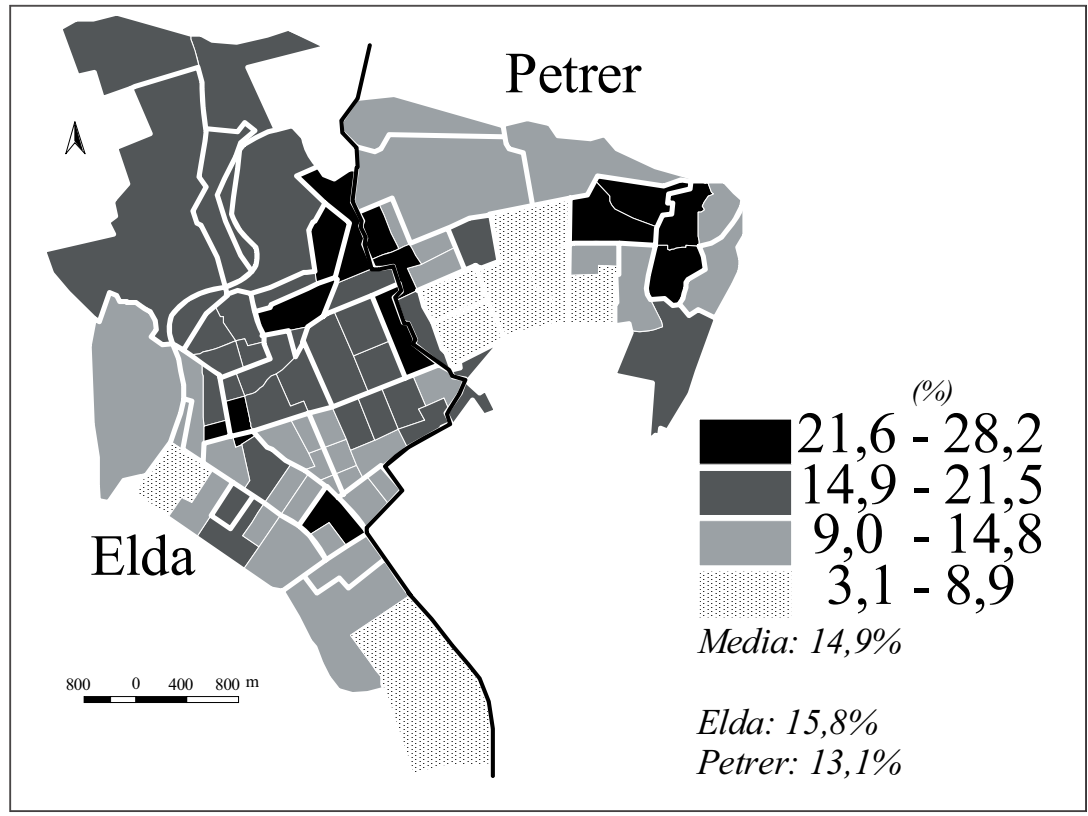

Fuente: Padrón municipal de habitantes 2003. Elaboración propia. 
MaPA 8. Elda-Petrer 2003. Índice de dependencia

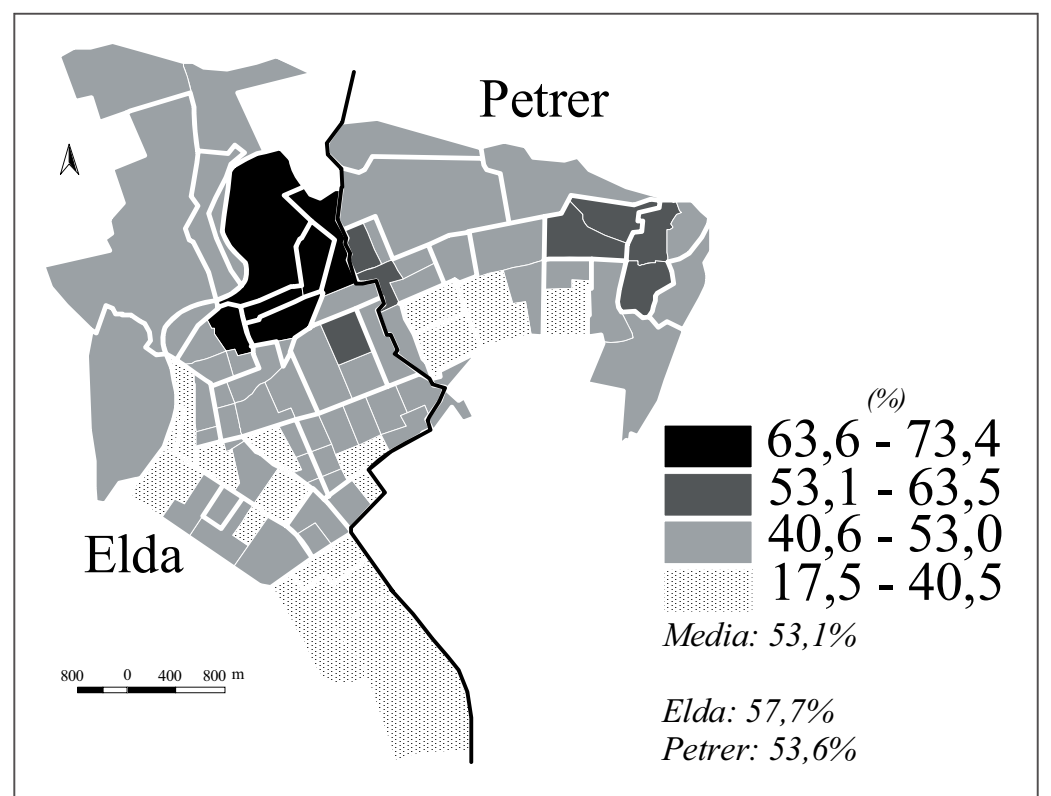

Fuente: Padrón municipal de habitantes 2003. Elaboración propia.

MAPA 9. Elda-Petrer 2003. Índice de maternidad

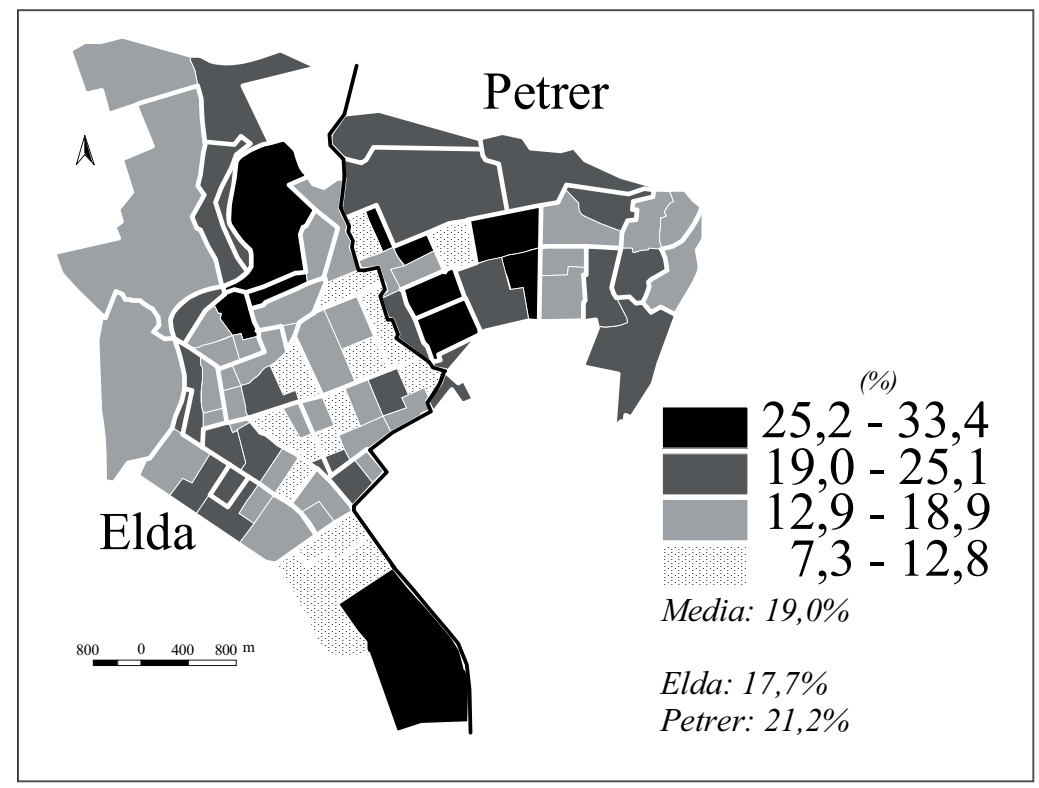

Fuente: Padrón municipal de habitantes 2003. Elaboración propia. 
un índice de dependencia juvenil de 34,9\%, frente al 30\% de Elda; y, de modo inverso, esta última ciudad tiene el índice de dependencia de la población vieja de $22,7 \%$ contra el $18,7 \%$ de Petrer. En ese sentido puede apreciarse cómo parte de la población joven de Elda ha desplazado su residencia al municipio vecino.

Respecto a los mayores índices de dependencia de ancianos los encontramos en Elda en barrios como los de San Francisco, alrededores de la plaza de Toros, algunos sectores de la Fraternidad, los alrededores de la Plaza de la Concordia y el Progreso, mientras en Petrel son el Casco Viejo y el Ayuntamiento y sus alrededores.

Por otro lado los barrios con los menores índices de dependencia se hallan en su mayoría en los nuevos espacios edificados de ambas ciudades, con excepción del barrio de la Tafalera en Elda donde continúa vigente la situación de años anteriores: un espacio antiguo degradado con mucha población joven (mapa 8).

El índice medio de maternidad para ambos municipios en 2003 supone que por cada 100 mujeres en edad fecunda (entre 16 y 45 años de edad) hay 19 niños entre 0 y 4 años. Pero tomando por separado los datos de ambos municipios, podemos apreciar que el índice de maternidad en Petrer es mayor, $21,2 \%$, contra $17,7 \%$ en Elda. Volvemos a relacionar esta tendencia con la existencia de una población más joven en Petrer, además de la existencia de áreas residenciales de reciente construcción como el Campet y las Chimeneas. En Elda esta proporción es mayor en el barrio de la Tafalera, en este caso como resultado de una mayor fecundidad de las mujeres en zonas marginales (mapa 9).

\subsection{Movimientos migratorios recientes}

Hoy no podríamos concebir la conurbación Elda-Petrer sin el elevado número de habitantes que han llegado desde otras partes de España. Puede decirse que Elda se consolidó como ciudad gracias al gran número de personas que acudieron a ella entre 1960 y 1980. Las áreas de procedencia de esta población eran Castilla la Mancha, Andalucía y Murcia y para el año 2001 éstos suponen alrededor de un cuarto de la población total, sin contar con los hijos que ya han nacido en el municipio de Elda. A ese respecto interesa conocer el lugar de nacimiento de la población establecida en ambos municipios, la cual es reflejo de los procesos migratorios recientes. Igualmente contrasta la proporción de población nacida en el mismo municipio, que para el caso de Elda en 2001 supone el 47,5\% del total, mientras que para Petrer esa cifra sólo representa el 26,2\%, en lo que sin duda interviene los nacimientos de la comarca que se producen en el hospital de Elda, después registrados en su Registro Civil. Por el contrario y por el mismo motivo las proporciones son inversas para la población nacida en otros municipios de la provincia de Alicante, en donde Elda tiene el $23,3 \%$ y Petrer el 47,5\% de su población. La población nacida en otras provincias y en el extranjero, que miden con más nitidez la inmigración, en Elda suma el 29,2\% del total y el $26,3 \%$ en Petrer, cifras cercanas pero con manifiesta primacía para la atracción inmigratoria de Elda.

Cuadro 5

ELDA-PETRER 2001. LUGAR DE NACIMIENTO DE LA POBLACIÓN

\begin{tabular}{|l|c|c|c|c|}
\hline & En la misma ciudad & En la misma provincia & En otras provincias & En el extranjero \\
\hline Elda & 47,5 & 23,3 & 26,9 & 2,3 \\
\hline Petrer & 26,2 & 47,5 & 24,5 & 1,8 \\
\hline
\end{tabular}

Fuente: INE, Censos de población de España. 2001 
La inmigración extranjera empadronada en el año 2003 suma el 4,5\% de la población eldense, mientras que en 2001 era el 2,3\% y en 1991 esa cifra superaba por muy poco el $1 \%$, lo que destaca el carácter muy actual de este flujo. Durante los años sesenta los inmigrantes nacionales acudían a Elda como mano de obra para la industria del calzado, hoy la inmigración extranjera desempeña primordialmente labores domésticas, las mujeres, y trabajos ocasionales en la industria auxiliar del calzado, todos. Esa especialización laboral, unida a la existencia de barrios donde la población autóctona se ha desplazado a los nuevos barrios, determina en gran medida que queden viviendas en barrios más o menos centrales para ser vendidas o alquiladas a los inmigrantes extranjeros. De este modo se configuran en la ciudad unos espacios donde la población tiene altas tasas de feminidad, hay tendencia al envejecimiento y al despoblamiento de la población joven; de modo que los inmigrantes se establecen allí conviviendo con los españoles de menor capacidad adquisitiva en algunas zonas obreras concretas. No obstante conviene apuntar ciertos matices. Las mayores tasas de inmigrantes extranjeros coinciden en las proximidades de la Plaza Castelar, una de las zonas con mayores rentas, pues aquí se establecen mujeres inmigrantes que trabajan en el servicio doméstico. Esta inmigración extranjera se localiza por un lado en los sectores más antiguos de los barrios de ambas Fraternidades, y por otro en el cinturón urbano que queda entre el centro funcional y los nuevos espacios periféricos de reciente construcción. Esta situación refleja cómo los inmigrantes se establecen en las proximidades de las zonas más acomodadas de la ciudad; mientras es difícil encontrarlos en los barrios obreros tradicionales más alejados del centro, y en los barrios edificados más recientemente.

MAPA 10. Proporción de inmigrantes extranjeros

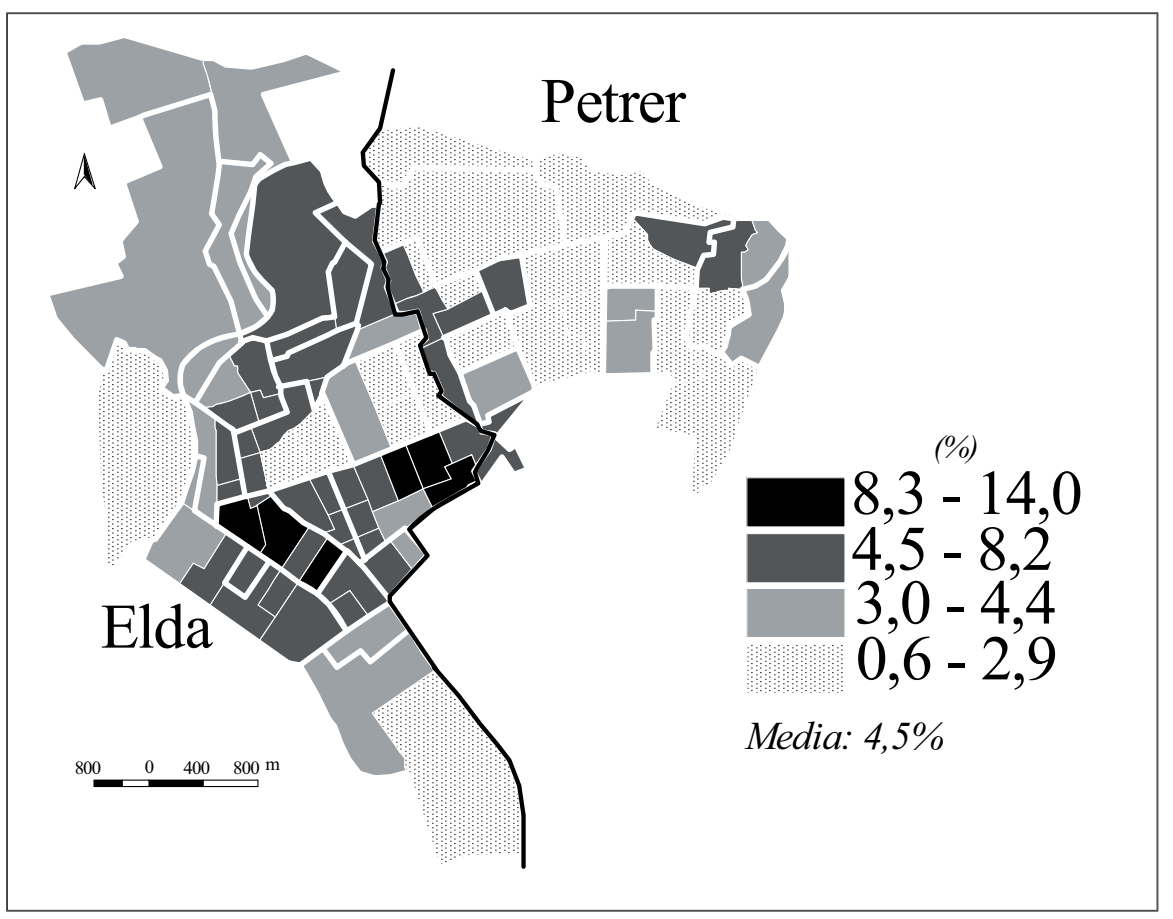

Fuente: Padrón municipal de habitantes. 2003. Elaboración propia. 
Los datos comentados reflejan a los inmigrantes extranjeros empadronados en Elda, aunque se debe afrontar que existe un cierto número de inmigrantes que no figuran en los registros oficiales, pudiendo aumentar el porcentaje de inmigrantes del municipio hasta el 6,5\%. En concreto esta población reside en la Avenida de Alfonso XIII hasta la de las Olimpíadas, teniendo en cuenta los enclaves de San Francisco, Nueva Fraternidad, y las Trescientas.

Debemos hacer una referencia a la inmigración en Petrer, ya que ésta, junto a la de Elda, forma parte de la misma realidad socioeconómica de la conurbación, participando de la misma forma en la movilidad interurbana existente entre ambos municipios. De este modo, en el año 2003 la población inmigrante extranjera empadronada en Elda ascendía a 2.482 personas y en Petrer a 1.050, suponiendo la población de origen colombiano casi el $50 \%$ del total. Las pautas de localización urbana de los inmigrantes extranjeros en Petrer sigue el mismo modelo que para Elda, es decir, los inmigrantes residen en aquellos sectores urbanos consolidados que ni coinciden con las nuevas áreas urbanizadas ni con el centro funcional económicamente más activo.

\subsection{El nivel de instrucción}

La popularización de la educación y la obligatoriedad escolar hasta los 16 años de edad ha supuesto un aumento del nivel de instrucción. Si a ello añadimos que la población analfabeta y sin estudios se halla en general entre los estratos de población con más edad, vemos cómo hay cambios en la instrucción de la población según los barrios. La movilidad de población entre Elda y Petrer, también ha tenido incidencia en ese aspecto, ya que, por ejemplo, existen zonas en donde la mayor tasa de juventud en sus habitantes se traduce en mejora del nivel de educación, sobre todo en la Educación General Básica o Primaria.

Los barrios con mayores tasas de analfabetismo se encuentran en los lugares donde coincide una tasa más alta de población mayor y fuerte presencia de inmigrantes desde otras autonomías. Para el año 2003 la tasa de analfabetismo para ambos municipios es de $5,2 \%$ de la población mayor de 16 años. Pero en el municipio de Elda la tasa es 4,8\% y en Petrer 6\%, es decir tasas muy altas si las comparamos con la de otros municipios de características sociolaborales semejantes, como Elche, donde en 1996 la tasa de analfabetos sobre población de 10 y más años es de 3,1\% (LARROSA, J. A., 2000). A grandes rasgos existen dos zonas claramente identificadas donde la proporción de analfabetos es inferior a la media: un primer sector coincide con las áreas centrales de Elda, mientras el segundo sector se corresponde con las nuevas áreas de reciente edificación, tanto de Elda como de Petrer.

Por el contrario, las mayores tasas de analfabetos se localizan en los primeros barrios periféricos levantados en el sector occidental de Elda, mientras que en Petrer las mayores tasas coinciden con el Casco Antiguo, alrededores del Castillo y algunas calles perpendiculares a la Avenida de Elda (mapa 11).

La población con estudios universitarios finalizados, representa el 5,7\% del total de la conurbación, pero para Elda esta cifra es del 6,4\% y para Petrer del 5,1\%. La localización residencial de los universitarios en Elda-Petrer no ha variado respecto a las cifras del año 1991, que principalmente en el centro de Elda, y con menor intensidad en los barrios que la rodean. Otra zona que presenta cifras similares es la prolongación de la Avenida de Ronda junto al nuevo Polideportivo; en relación a Petrer esta zona se encuentra en las viviendas de baja densidad existentes en los alrededores del Campet y en zonas del centro urbano (mapa 12). 
MAPa 11. Elda-Petrer 2003. Proporción de población analfabeta (mayores de 16 años).

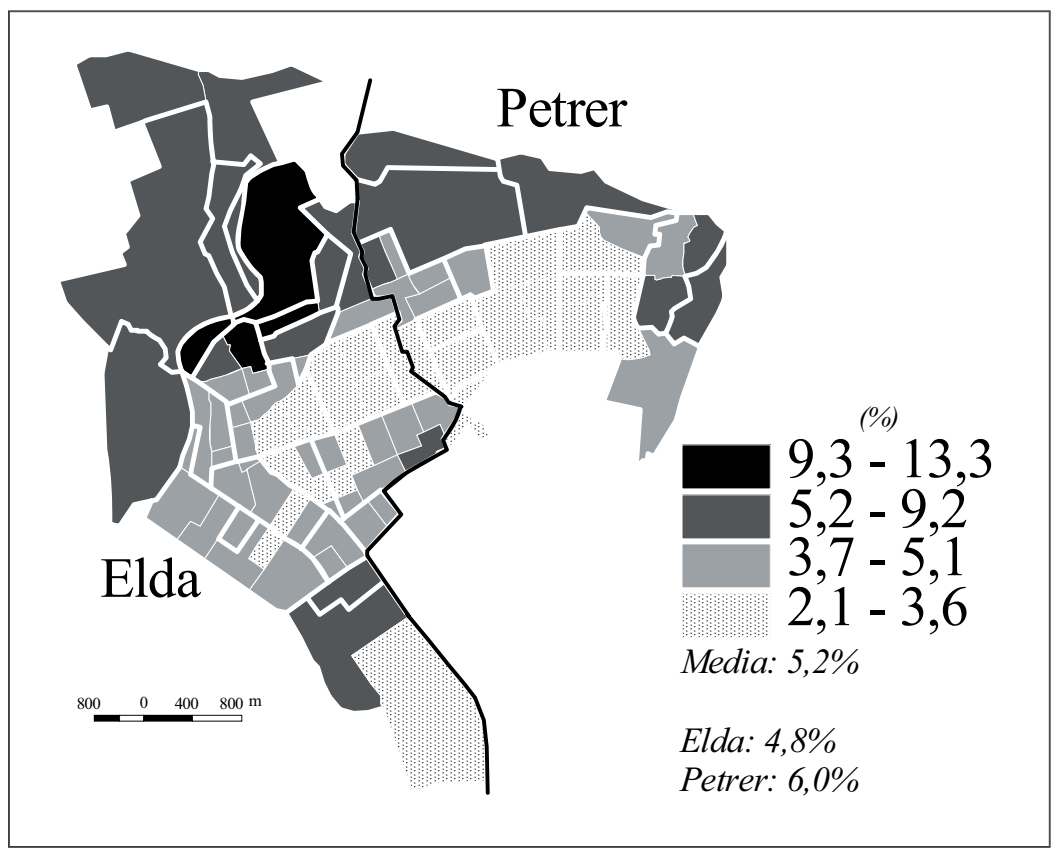

Fuente: Padrón municipal de habitantes. 2003. Elaboración propia.

MAPA 12. Elda-Petrer 2003. Proporción de población con estudios universitarios.

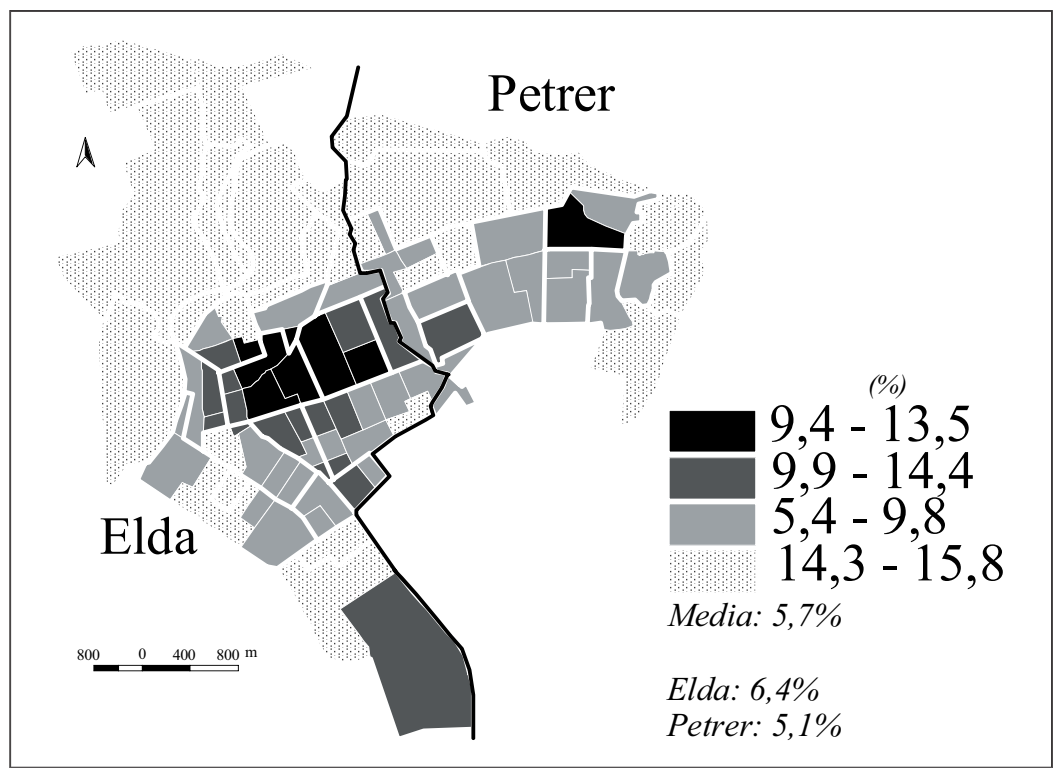

Fuente: Padrón municipal de habitantes. 2003. Elaboración propia. 


\section{Conclusiones cara al futuro}

Tras los análisis realizados sobre la conurbación de Elda-Petrer, conviene plantearse cuál es la situación actual y qué perspectivas ofrece para el futuro. También se ha de tener en cuenta que una conurbación de las características de Elda-Petrer presenta gran complejidad a la hora de analizarla y de aplicar propuestas de mejora, ya que entran en juego multitud de agentes de orden económico, político y social para los que en ocasiones resulta difícil encontrar puntos en común. Si a ello añadimos la fuerte reprocidad entre Elda y Petrer y las relaciones con otros territorios, ya sea de dentro o de fuera de la provincia de Alicante, llegaremos a la conclusión que cualquier propuesta de desarrollo que se plantee tiene ante todo que ser extensible a otros espacios.

En efecto, la escala local es aquella en la que los ciudadanos perciben si las políticas e inversiones realizadas han calado realmente y con ello se manifiesta un aumento de la calidad de vida. Pero la realidad económica, la gestión política, la atracción de iniciativas tanto públicas como privadas, el respeto al patrimonio natural y cultural y el fomento del asociacionismo e implicación de los ciudadanos, es lo que en definitiva marca el desarrollo de los municipios. Con anterioridad se ha venido señalando que las relaciones sociales y la movilidad entre Elda y Petrer es muy intensa. En cambio la relación entre ambos ayuntamientos podría incrementarse. Existe una serie de actividades que de emprenderlas en común supondrían un ahorro económico para los ciudadanos de ambos municipios: la recogida de basuras, el alumbrado, el transporte público, el servicio de la ORA, la limpieza, las obras, la compra de diversos materiales, etc.., en definitiva se trata de tener más capacidad de presión frente a empresas que prestan sus servicios a los ayuntamientos. Negociar por separado implica de partida una posición de inferioridad respecto al interlocutor, lo que incide de modo negativo en los ciudadanos. Es compatible la existencia de dos unidades políticas e identidades culturales, con la existencia de servicios públicos para ambas ciudadanías.

Volviendo a la actual coyuntura sociodemográfica de Elda-Petrer, y tratando de predecir futuros comportamientos, podemos distinguir una serie de debilidades y amenazas que pueden poner en riesgo el tejido social de esta conurbación; de modo que hay que tratar de corregirlas en la medida de lo posible. Como una de las debilidades principales hay que distinguir la fuerte dependencia de la economía local respecto a la industria del calzado, que está llamada a corto y medio plazo a realizar cambios si quiere, o bien permanecer o bien mantenerse mientras que se buscan nuevas alternativas. Por otro lado, podemos identificar como debilidad la existencia de barrios que no se hallan integrados en el conjunto de la ciudad, ni desde el punto de vista social ni desde la estructura urbana, porque presentan un callejero que a duras penas encaja con el resto de la ciudad, concentrándose en ellos suelo residencial e industrial con los problemas de tráfico, falta de zonas de esparcimiento y carencia dotacional que ello genera. Otra de las carencias es la concentración de la oferta de servicios en espacios muy concretos, lo cual genera una enorme cantidad de desplazamientos que en las horas punta se hacen insostenibles. En ese sentido los problemas de tráfico que tienen que soportar los vecinos inciden en la calidad de vida de los mismos y en la imagen que se tiene de la ciudad. Otra de las debilidades se deduce de los datos demográficos y del año de construcción de algunas viviendas, que muestran cómo se están configurando barrios en donde la población joven se marcha a otros sectores, quedándose la población más vieja y la de menor poder adquisitivo, jóvenes con pocos recursos y bajo nivel de instrucción (el Progreso, Polígono Almafrá, las Tenerías). En ese sentido es necesario realizar inversiones y aplicar políticas que dinamicen esos sectores tal y como se viene haciendo, por ejemplo, con los centros históricos de muchas ciudades. 
El no valorar parte del patrimonio natural y cultural existente dentro de estos municipios, supone la no apuesta por recursos muy valiosos para el esparcimiento y disfrute de la ciudadanía. Ese descuido o falta de difusión que estos espacios tienen para el futuro de la ciudad, puede conllevar un deterioro irreversible de los mismos. De la misma manera hay edificios significativos dentro de las dos ciudades que no se valoran adecuadamente. El caso más significativo es el del Castillo de Elda, que pese a los esfuerzos realizados durante los últimos años, aún no es suficiente, siendo necesario para su reconstrucción una implicación más decidida de las administraciones públicas y privadas. Con un correcto planeamiento urbano, zonificación de los usos del suelo y valorización de los recursos naturales-culturales, sería más fácil una diversificación de la economía y atraer nuevas actividades que complementen a la industria. Ésta debe afrontar el reto que supone la entrada en los mercados tradicionales de productos fabricados en otros países mediante un aumento de la productividad, la formación especializada de técnicos y trabajadores y la búsqueda de nuevos mercados. En este punto conviene señalar que Petrer o los municipios vecinos no son la competencia directa para Elda, sino que conviene trazar estrategias comunes de actuación supracomarcal que determinen, compensen, equilibren y racionalicen la especialización productiva de estos municipios a largo plazo. Sólo con estrategias y planteamientos globales aplicados en la escala local, podrán articularse medidas que incidan en el desarrollo y mantenimiento de los estándares de calidad de vida de los municipios.

Por otro lado hay que considerar que estos municipios poseen unas características desde el punto de vista territorial y humano que determinan ciertas oportunidades de desarrollo, que bien gestionadas pueden pasar a formar parte de las fortalezas de ambas ciudades. De este modo no podemos olvidar el emplazamiento privilegiado de Elda; por un lado está el Arco Mediterráneo que le otorga unas ventajas que en otros territorios no existen y, por otro lado, Elda-Petrer se sitúa en el centro del Valle del Vinalopó, a través del cual entran en contacto los flujos procedentes de la meseta con los desarrollos económicos del litoral mediante la red de autopistas, carreteras y ferrocarriles. Además existe una tradición empresarial muy arraigada, que por un lado siempre ha sido capaz de atraer inversiones, y por otro ha tenido una clara voluntad exportadora. $\mathrm{Si}$ a esto añadimos la determinación de invertir en la formación y capacitación del capital humano, investigar y desarrollar nuevas tecnologías y consolidar y buscar mercados, se garantizaría de modo notable el proyecto de ciudad desarrollada. Otro aspecto positivo de la conurbación es la existencia de un gran número de colectivos de ciudadanos que, si ya participan en la vida cultural y social local, también pueden hacerlo para desarrollar y colaborar en el proyecto de conurbación, en ese sentido es necesario escuchar a los ciudadanos y que éstos se impliquen en el futuro de la zona.

De igual forma hay algunos aspectos negativos que mediante un consenso de todos los agentes ciudadanos y un esfuerzo común por mejorarlos, pueden convertirse en beneficios urbanos aprovechables para incrementar la calidad urbana y devenir en potenciales recursos para otras actividades; por ejemplo la recuperación de espacios urbanos degradados, evitando así la movilización de más suelo urbanizable y destinando esos espacios a lugares de esparcimiento. Otro aspecto a considerar es la necesidad de un cambio en la mentalidad de búsqueda constante de inversiones foráneas; la globalización de la economía y la salida de la Comunidad Valenciana como Región Objetivo 1 de la Unión Europea, va a reducir en poco tiempo la llegada de recursos económicos. En relación a esto hay que apostar por las iniciativas que, aprovechando las potencialidades de la ciudad, surjan desde los emprendedores locales. En ese sentido hay que aprovechar la «marca Elda-Petrer» para colocar los productos de modo más decidido en los mercados oportunos, sin olvidarse nunca del nacional. También debe aprovecharse el hecho de que Elda-Petrer es el tercer núcleo urbano 
más poblado de la provincia de Alicante (en 2004 según el INE tenía 85.341 habitantes), por detrás de la capital y de Elche. Este hecho no es sólo importante por la cantidad de personas que se concentran, sino también por la red de ciudades que gravitan en torno a ellas. Sin lugar a dudas todos estos aspectos positivos se verían potenciados en el momento que hubiera una decidida determinación por el incremento de las inversiones en conceptos de formación y capacitación de los ciudadanos, tanto a nivel académico como profesional, y por las inversiones en $\mathrm{I}+\mathrm{D}+\mathrm{I}$.

A otro nivel de análisis podemos identificar una serie de tendencias generales que desde el punto de vista sociodemográfico marcarán las principales características de la estructura y dinámica de la población a medio y largo plazo:

- Evolución demográfica tendente a la estabilización de la población. Aumento de inmigrantes extranjeros. Durante casi todo el siglo XX, Elda y Petrer tuvieron un crecimiento constante de su población, sobre todo durante los años sesenta y setenta, debido en primer lugar a los saldos migratorios y en segundo al saldo natural. Un punto de inflexión a esa dinámica comienza a mediados de los setenta, tendencia que devino para Elda incluso en crecimiento negativo ya comenzada la década de los noventa, como consecuencia de la estabilidad de los saldos naturales y de saldos migratorios negativos. No obstante, es a partir del año 2000 cuando la llegada de inmigrantes extranjeros ha equilibrado la balanza de Elda para situarla de nuevo en cifras superiores a los 54.000 habitantes (en 2004 según el INE tenía 54.086).

Diferencias entre la estructura demográfica de Elda y Petrer. El envejecimiento de la población. La progresiva estabilización de la población durante los años ochenta, la crisis de la industria del calzado iniciada a principios de los noventa, la madurez del PGOU de Elda y la puesta en valor del PGOU de Petrer, determinaron en gran medida un continuo trasvase de población joven desde Elda hacia Petrer. El resultado aceleró en parte el éxodo de población joven de determinados barrios tradicionales eldenses hacia nuevos espacios urbanos. Como consecuencia aumentó la edad media de esos barrios, transformándose el perfil habitual de los vecinos. De este modo convivía población vieja con jóvenes de poco nivel adquisitivo, y a partir del 2000 con población procedente del extranjero. En cualquier caso la estructura por edades determina que en Elda haya un nivel de población más envejecida que en Petrer. El crecimiento de inmigrantes extranjeros y el progresivo envejecimiento de la población es uno de los rasgos demográficos de mayor importancia que presenta Elda a principios de siglo XXI. Esta coyuntura es necesaria tenerla en cuenta para predecir futuros comportamientos poblacionales y planificar y adaptar los servicios y las dotaciones necesarias para la futura estructura demográfica de Elda. Por otra parte también es preciso corregir la estructura de la instrucción, sobre todo de la población con estudios universitarios.

\section{Bibliografía}

BERNABÉ MAESTRE, J.M (1976): La industria del calzado en el Valle del Vinalopó. Valencia, Departamento de Geografía. 236 pp.

CAPEL, H. (1975): Capitalismo y morfología urbana en España, Universidad de Barcelona, 142 pp.

GOZÁLVEZ PÉREZ, V. y otros (1987): Atlas sociodemográfico de la ciudad de Alicante, Alicante, Instituto de Cultura Juan Gil Albert, 143 pp.

LARROSA ROCAMORA, J.A. (2000): Atlas demográfico y social de la ciudad de Elche, universidad de Alicante, Ajuntament d'Elx, 286 pp.

PONCE HERERO, G. (1991); Análisis urbano de Petrer: estructura urbana y ciudad percibida. Alicante. Edita Universidad de Alicante y Ayuntamiento de Petrer, 145 pp. 
PONCE HERRERO, G. y RAMOS HIDALGO, A. (2000): «Planeamiento urbano e industria en la conurbación Elda-Petrer» en Revista del Vinalopó, 3. Dossier Organització i ordenació del territori. Edita Centre d'Estudis Locals del Vinalopó. Petrer, pp. 87-104.

RAMOS HIDALGO, A. y otros (1996): Ordenación del territorio y planificación estratégica en el eje de desarrollo económico del Vinalopó. Alicante. Universidad de Alicante, 196 pp.

ROSSELLÓ i VERGER, V. (1984): 55 ciutats valencianes, Universitat de València, València, 280 $\mathrm{pp}$

SAMPER ALCARAZ, J. (1995): Elda a través de la historia. Comunidad humana y territorio, Ayuntamiento de Elda y Universidad de Alicante, Elda, 215 pp.

VALERO ESCANDELL, J.R. (1992): Elda, 1832--1980 industria del calzado y transformación social, Alicante, Instituto de Cultura Juan Gil-Albert, 198 pp.

VV.AA. (1985): Diagnosis del Plan General de Ordenación Urbana de Elda, 308 pp. 